\title{
Hydroxysteroid Dehydrogenase Inhibitor
}

National Cancer Institute

\section{Source}

National Cancer Institute. Hydroxysteroid Dehydrogenase Inhibitor. NCI Thesaurus.

Code C54678.

Any substance that inhibits hydroxysteroid dehydrogenase, an enzyme that catalyzes the interconversion of hydroxyl and carboxyl groups on steroids, leading to activation or deactivation of the steroid molecule. Inhibition of hydroxysteroid dehydrogenase can be used as a treatment for esophageal ulceration and inflammation. 